\title{
A APLICABILIDADE DA FUNÇÃO SOCIAL DA PROPRIEDADE EM FACE DA MULTIPROPRIEDADE
}

\author{
Danielle Zapani* \\ Levi Hülse* \\ Anemari Socreppa ${ }^{* *}$
}

\begin{abstract}
RESUMO
$\mathrm{O}$ artigo versa sobre a aplicabilidade do princípio da função social da propriedade no instituto da multipropriedade, de forma a fomentar o desenvolvimento econômico e impulsionar a aquisição compartilhada de bens imóveis. Será estudado o direito de propriedade, seu histórico até chegar na Constituição Federal e no Código Civil. Em um segundo momento o estudo analisará o princípio da função social da propriedade e suas peculiaridades. E, por fim, será invocado o instituto da multipropriedade, suas diferenças com o condomínio comum, bem como a aplicabilidade da função social no instituto da multipropriedade. Conclui-se, portanto, que presente estudo é importante para apresentar à sociedade uma nova forma de fracionamento de imóveis, possibilitando à uma grande parte da população a aquisição de um quota parte de imóvel
\end{abstract}

\footnotetext{
*Acadêmica da $10^{\text {a }}$ fase do Curso de Direito, da Universidade Alto Vale do Rio do Peixe - Caçador - SC.

** Doutorando em Ciência Jurídica pela Universidade do Vale do Itajaí - UNIVALI - SC, na área de concentração em Constitucionalismo, Transnacionalidade e Produção do Direito. Mestre em Ciência Jurídica pela UNIVALI. Graduado Bacharel em Direito pela Fundação Universidade Regional de Blumenau FURB (2010) e graduado em História pela Fundação Universidade Regional de Blumenau FURB (2006). Advogado com a OAB/SC 31.986. Professor na Universidade do Alto Vale do Rio do Peixe - UNIARP. O autor agradece ao Fundo de Apoio à Pesquisa (FAP) da UNIARP pelo apoio financeiro. E-mail: levi@uniarp.edu.br

*** Professora da Disciplina de Teoria Geral do Processo da Universidade Alto Vale do Rio do Peixe. Especialista em Direito Empresarial pela Unoesc - Joaçaba/SC, em Ciências da Magistratura pela Esmesc/UnC - Curitibanos/SC, em Processo Civil pela Universidade Anhanguera Uniderp. Mestre Interdisciplinar em Desenvolvimento e Sociedade pela Universidade Alto Vale do Rio do Peixe. Técnica Judiciária Auxiliar no Tribunal de Justiça do Estado de Santa Catarina.
} 
em local de férias ou veraneio, fomentando a economia preservando o meio ambiente.

PALAVRAS-CHAVE: Propriedade; Princípio da Função Social; Condomínio; Multipropriedade.

\begin{abstract}
The article deals with the applicability of the principle of the social function of property in the institute of timeshares, in order to foster economic development and boost the shared acquisition of real estate. It will study the right to property, its history until arriving at the Federal Constitution and the Civil Code. In a second moment the study will analyze the principle of the social function of the property and its peculiarities. And, finally, will be invoked the institute of the multipropriety, its differences with the common condominium, as well as the applicability of the social function in the institute of the multipropriety. It is concluded, therefore, that this study is important to present to society a new form of fractionation of real estate, making it possible for a large part of the population to acquire a share of the property in a vacation or summer resort, fomenting the economy preserving the environment.
\end{abstract}

KEY WORDS: Property; Principle of the Social Function; Condominium; Multipropriety.

\title{
RESUMEN
}

El artículo versa sobre la aplicabilidad del principio de la función social de la propiedad en el instituto de la multipropiedad, para fomentar el desarrollo económico e impulsar la adquisición compartida de bienes inmuebles. Se estudiará el derecho de propiedad, su histórico hasta llegar a la Constitución Federal y al Código Civil. En un segundo momento el estudio analizará el principio de la función social de la propiedad y sus peculiaridades. Y, por último, será invocado el instituto de la multipropiedad, sus diferencias con el condominio común, así como la aplicabilidad de la función social en el instituto de la multipropiedad. Se concluye, por lo tanto, que este estudio es importante para presentar a la sociedad una nueva forma de fraccionamiento de inmuebles, posibilitando a una gran parte de la población la adquisición de una cuota de inmueble en un lugar de vacaciones o veraneo, fomentando la economía preservando el ahorro medio ambiente.

PALABRAS CLAVE: Propiedad; Principio de la función social; condominio; Comparte el tiempo. 


\section{INTRODUÇÃO}

O presente artigo apresenta como tema fundamental a função social da propriedade aplicada no modelo de aquisição fracionada no tempo de bens imóveis, denominada multipropriedade.

O tema torna-se atual em razão da situação econômica do nosso país, onde se vislumbra o turismo como uma influente fonte de renda, haja vista que determinadas cidades atraem milhares de pessoas, inclusive de outras regiões, em épocas de alta temporada, veraneio e demais épocas que ensejam o turismo.

A multipropriedade se caracteriza pela divisão temporal, haja vista que o direito de domínio é praticado nos limites de tempo dentro do calendário. Esse instituto vem à tona com o objetivo de fomentar o giro da economia durante todos os meses do ano, ou seja, fracionar as quotas de acordo com as semanas do ano afim de que diferentes pessoas, que adquiram frações correspondentes à semanas predeterminadas, frequentem o mesmo local.

Analisar-se-á o brevemente sobre o direito de propriedade, levando em consideração a sua evolução até ser reconhecido pela legislação brasileira, bem como suas peculiaridades e importância no meio jurídico. Após isso, relacionar-se-á as formas de aquisição de propriedade imóvel, com todas as características, bem como será conceituado, de forma breve, o instituto da multipropriedade.

Ainda, tratar-se-á sobre o princípio da função social da propriedade, seu conceito e principais características bem como previsão legal, diferenciação sobre a propriedade urbana e rural.

E por fim, estudar-se-á sobre a multipropriedade, exibindo sua origem e histórico, bem como sua previsão legal no direito comparado. Ainda, analisar-se-á as diferenças do presente tema com o instituto do condomínio, com verificação da possibilidade ou não da aplicabilidade do princípio da função social da propriedade no instituto da multipropriedade, de forma a entender se o instituto viabiliza o desenvolvimento social e econômico da sociedade.

\section{PROPRIEDADE}

Desde o início do convívio em grupos de pessoas, surgiu a 
necessidade de determinar alguns direitos a fim de possibilitar uma convivência pacífica e organizada. $\mathrm{O}$ direito de propriedade é um típico exemplo dessa necessidade de adaptação (FARIAS, 2009, p. 164).

Nos primórdios entendia-se que a propriedade pertencia à coletividade. Porém a ideologia liberal e individualista tornou possível que os sujeitos expressassem sua vontade, a partir deste marco começou a se desenvolver a ideia de titularidade da propriedade (VENOSA, 2017, p. 174).

Em síntese, entende-se por propriedade o direito subjetivo, que tem a pessoa física ou jurídica, de usar, gozar e dispor de um bem, corpóreo ou incorpóreo, bem como reivindicá-lo de quem injustamente o detenha (MIRANDA, 1959, p. 9).

No Brasil, a propriedade privada imobiliária passou por um longo processo para deixar de fazer parte do patrimônio público e integrar a esfera privada. O direito de propriedade consta de nossa Lei Maior dentre os direitos e garantias fundamentais ao lado dos valores da vida, liberdade, igualdade e segurança (FARIAS, 2009, p. 167).

A Constituição Federal de 1988 prevê o direito de propriedade no artigo $5^{\circ}$, inciso XXII, bem como pode ser encontrada sua previsão no Código Civil, no artigo 1.225, inciso I, que a define como sendo um direito real (BRASIL, 2017).

Além disso, o Código Civil descreve o direito de propriedade com todas as suas faculdades e prerrogativas, quais sejam: usar (jus utendi), o direito de gozar (jus fruendi) e o poder da disposição da coisa (jus abutendi) (FARIAS, 2009, p. 168).

Quanto às formas de aquisição da propriedade imóvel, conforme previsto na legislação brasileira, são obtidas as formas de procedência originárias e derivadas, a título singular e universal, e suas espécies estão inseridas a partir do artigo 1.238 (VENOSA, 2017, p. 198).

\section{A FUNÇÃO SOCIAL DA PROPRIEDADE}

Mesmo estando amplamente protegido pela lei, o poder do proprietário em deliberar sobre o aproveitamento de seu terreno está constantemente se submetendo ao interesse coletivo, de forma que respeite o planejamento urbanístico do local de situação do imóvel em prol do benefício da coletividade (CHALHUB, 2014, p. 70). 
A função social, elemento essencial do direito de propriedade, em virtude de sua importância, passou a integrar os textos das Constituições brasileiras, sendo que, atualmente, integra inclusive o rol de direitos e garantias fundamentais, o que lhe concede inúmeras vantagens em razão de seu status constitucional (FARIAS, 2009, p. 201).

A Constituição da República Federativa do Brasil de 1988, em seu artigo $182, \S 2^{\circ}$ dispõe que a propriedade urbana cumpre sua função social quando atende às exigências fundamentais de ordenação da cidade, expressas no plano diretor (BRASIL, 2017).

Quanto ao imóvel rural, é dever do proprietário cumprir algumas obrigações para fazer valer a função social da propriedade, no que tange à interesses coletivos, como a observância das obrigações trabalhistas. Já no sentido dos interesses difusos, por exemplo, cabe à ele zelar pela preservação ambiental (FARIAS, 2009, p. 220).

Aplicando o princípio da função social da propriedade, com relação ao imóvel urbano, é possível redirecionar os recursos e a riqueza de forma mais precisa, sempre em busca da diminuição das desigualdades sociais e econômicas (FARIAS, 2009, p. 220).

Se torna mais fácil de vislumbrar a aplicabilidade do princípio da função social da propriedade quando nos deparamos com as leis que fomentam a regularização fundiária para a população de baixa renda, gerando um resgate material, com a finalidade de conseguir um maior equilíbrio no contexto social, reduzindo as desigualdades e facultando à todos o acesso ao direito de propriedade (PAIVA, 2017, p. 213).

Desta forma, o principal objetivo da função social inserida em nossa Carta Magna é fomentar a busca por cidades autossustentáveis, que vedem utilização de áreas incompatíveis com os benefícios sociais almejados, evitando a ociosidade de áreas, potencializando o uso de alguns lugares, serviços e equipamentos, estimulando, desta maneira, o desenvolvimento econômico e cultural (GUIMARAENS, 2017).

\section{A MULTIPROPRIEDADE}

O conceito tradicional de propriedade vem deixando de ser o único existente em razão da contínua evolução da sociedade. Em 
face das mudanças na coabitação de grupos, é imprescindível que o direito esteja sempre se atualizando e, consequentemente, sendo adaptado, de forma a resguardar novos interesses e se moldar conforme a necessidade da população (RIBEIRO, 2017).

Nesse vértice, destaca-se $\mathrm{O}$ instituto da propriedade compartilhada, denominada time sharing ou multipropriedade, que apesar de não ser um tema recente, torna-se atual em virtude da situação econômica e social de nosso país (FARIAS, 2009, p. 164).

O sistema de propriedade compartilhada se caracteriza pela faculdade do titular em dividir o bem, e funciona como uma espécie de condomínio no espaço temporal. O seu objetivo é, basicamente, propiciar à todas as classes uma moradia de férias, ou segunda moradia, que pode ser adquirida por valor reduzido em razão da divisão realizada em quotas partes de tempo (FARIAS, 2009, p. 164).

$\mathrm{Na}$ multipropriedade evidencia-se a base material individualizada, pela divisão temporal nos limites de tempo dentro do calendário, para que o titular da quota possa exercer seu direito de dominus. Nesse instituto, é ideia é que a utilização do bem fique restrita a um período de tempo para cada um dos titulares do bem objeto de compartilhamento (RIOS, 2017).

Há uma discussão doutrinária e jurisprudencial com relação a admissibilidade do sistema de propriedade compartilhada no Brasil, pois há colisão com os princípios do numerus clausus, ou seja, rol taxativo e do numerus apertus, que se trata do rol exemplificativo (RIOS, 2017).

Há quem defenda que os direitos reais se tratem de numerus clausus, em razão da tipificação do artigo 167 da Lei de Registros Públicos, o que engessa o progresso social e do direito das coisas (RIOS, 2017).

De outro lado, Viegas de Lima, em trabalho inovador e ousado, defende a revisão da tipicidade ou numerus clausus dos direitos reais, possibilitando a admissão da multipropriedade imobiliária como direito real (VIEGAS DE LIMA, 1990, p. 198).

No que concerne ao condomínio tradicional, é possível extrair da doutrina as duas principais divisões históricas de direito condominial, quais sejam, Romana e Germânica. Nesta primeira, trata-se de uma concepção individualista, onde cada condômino exerce a propriedade em sua plenitude, respeitando o direito dos demais (VENOSA, 2017, 362). 
Ainda no Direito Romano, o condomínio se dá como uma situação transitória e desvantajosa, "onde o titular detém o direito a uma quota-parte de um todo não localizado em um primeiro momento" e ainda, o caráter transitório e incidental facilitam a extinção do condomínio, onde os condôminos podem sair a qualquer momento (MELO, 2017).

A tradição romana é adotada por nosso ordenamento jurídico, pois "traduz a natureza do condomínio com a modalidade de propriedade em comum com partes ideais". Além disso, a noção romana viabiliza a distribuição equitativa de direitos, levando em consideração que "cada condômino é proprietário, pode exercer os poderes inerentes à propriedade sobre a coisa". No entanto, há uma limitação do direito de usar, fruir e dispor em razão da convivência com os mesmos direitos dos demais condôminos (VENOSA, 2017, 362).

Além disso, se discute também a proximidade desse instituto com o condomínio tradicional, o qual, segundo alguns doutrinadores, pode sim ser aplicado analogicamente no time sharing afim de nortear a sua incidência no Brasil, porém há ressalvas de que, para a viabilidade da utilização do time sharing, é indispensável a convenção de condomínio (MELO, 2017).

Os estudos do presente artigo se desenvolveram sob a ótica da importância do cumprimento da função social da propriedade quando efetivamente utilizada a multipropriedade, afim de concretizar o principal alicerce da propriedade em tempo compartilhado, qual seja, permitir a utilização do bem de acordo com sua função econômica e social (MELO, 2017).

O sistema de propriedade compartilhada carrega consigo a incumbência de tornar frequentemente habitado o imóvel, por sua divisão em quotas no tempo, e em consequência à essa rotatividade de pessoas nos imóveis, a multipropriedade propicia a frequência e fluência do lazer, bem como crescimento do mercado de mão de obras, empregos à população local e, principalmente, enseja o turismo por mais tempo durante o ano, não somente em épocas de temporadas (RIOS, 2017).

Não obstante, o sistema da propriedade compartilhada, levando em consideração que mais pessoas vão dividir o mesmo espaço e não mais ocuparão vários imóveis, implicará na preservação 
do meio ambiente, evitando que mais construções sejam edificadas, indo de acordo com as disposições do princípio da função social da propriedade (MELO, 2017).

Nesse viés, importante destacar que a CF e o Código civil, ao introduzirem "a necessidade da propriedade exercer funções social e econômica, corrobora para a adoção da multipropriedade imobiliária condominial no Brasil, o que configura exemplo perfeito de conciliação entre desenvolvimento econômico e finalidade social" (MELO, 2017).

O sistema de time sharing tem força para incrementar o mercado imobiliário, concretizando direitos fundamentais e de ordem econômica, em razão de fomentar o desenvolvimento da região e satisfazer o interesse de seus usuários, contribuindo significativamente com o objetivo principal função social (SANTOS, 2017).

\section{CONCLUSÃO}

O presente estudo tratou sobre o direito de propriedade desde seu início, onde entendia-se que a propriedade pertencia à coletividade, o que foi modificado com a ideologia liberal e individualista, que tornou possível que os sujeitos expressassem sua vontade, a partir deste marco começou a se desenvolver a ideia de titularidade da propriedade.

O direito de propriedade consta de nossa Lei Maior dentre os direitos e garantias fundamentais, conforme artigo $5^{\circ}$, inciso XXII da Constituição Federal, bem como pode ser encontrada sua previsão no Código Civil, no artigo 1.225, inciso I, que a define como sendo um direito real. Além disso, o Código Civil descreve o direito de propriedade com todas as suas faculdades e prerrogativas, quais sejam: usar (jus utendi), o direito de gozar (jus fruendi) e o poder da disposição da coisa (jus abutendi).

Mesmo estando amplamente protegido pela lei, o poder do proprietário em deliberar sobre o aproveitamento de seu terreno está constantemente se submetendo ao interesse coletivo, de forma que respeite o planejamento urbanístico do local de situação do imóvel em prol do benefício da coletividade.

Essa submissão ao interesse coletivo é inerente ao direito assegurado, pois tem-se como base do direito de propriedade a função 
social, haja vista que a propriedade é instrumentalizada de forma a garantir o funcionamento do mercado e a evolução econômica.

Diante do exposto, é possível concluir que o sistema de propriedade compartilhada, denominado multipropriedade ou time sharing, atende plenamente o princípio da função social da propriedade, em razão de que, com a sua utilização, seria possível minimizar o número de construções, com consequente preservação ambiental, e melhor aproveitamento do bem.

Além disso, tem o objetivo de impulsionar o desenvolvimento econômico de regiões que sobrevivem de turismo, em razão da rotatividade de pessoas, fazendo a economia circular, gerando empregos e desenvolvimento sócio cultural.

Muitas são as problemáticas que envolvem o presente instituto, principalmente pela ausência de respaldo legal e delineamento de sua aplicação, que dificultam a sua inserção no sistema proprietário brasileiro.

Entretanto, a ideia basilar do instituto apresenta uma oportunidade de desenvolvimento socioeconômico, merecendo ser apreciada pelos legisladores e, inclusive, inserida no rol de direitos reais, permitindo o acesso da população aos seus benefícios com a devida segurança jurídica.

Discutir a complexidade do presente tema diante da atual conjuntura legislativa brasileira delongaria demais a presente monografia. Encerra-se, portanto, frisando a importância do aprofundamento do presente estudo, este que poderá vir a ser alvo de estudos mais aprofundados.

\section{REFERÊNCIAS}

BRASIL. Constituição da República Federativa do Brasil de 05 de outubro de 1988. Disponível em: http://www.planalto.gov.br/.

CHALHUB, Melhim Namem. Direitos Reais. 2. ed. São Paulo: Revista dos Tribunais, 2014.

FARIAS, Cristiano Chaves; ROSENVALD, Nelson. Direitos reais. 6. ed. Rio de Janeiro: Lumen Juris, 2009.

Direitos reais. 13. ed. Salvador: JusPodivm, 217. p. 164. 
GUIMARAENS, Maria Etelvina B. Função Social da Cidade e da Propriedade Urbana. Disponível em:

http://www.ibdu.org.br/imagens/funcaosocialdacidadeedapropriedadeurb ana.pdf.

MELO, Marcelo Augusto Santana de. Multipropriedade imobiliária. Disponível em: http://iregistradores.org.br/multipropriedade-imobiliaria/

MIRANDA, Pontes de. Tratado de direito privado. Direito das coisas. 2. ed. Vol. 20. Rio de Janeiro: Borsoi, 1959.

PAIVA, João Pedro Lamana. Registros públicos e a regularização fundiária da lei $\mathbf{n}^{\mathbf{0}} \mathbf{1 1 . 9 7 7 / 2 0 0 9}$. Disponível em: http://registrodeimoveis1zona.com.br/?p=295. Acesso em: 06 de junho de 2017.

RIBEIRO, Recielly Bruna Aquino; LIMA, João Paulo dos Anjos; CARREIRA, Ana Luiza. Multipropriedade Imobiliária. Disponível em: https://jus.com.br/artigos/48604/multipropriedade-imobiliaria.

RIOS, Arthur. Time Sharing ou Propriedade Compartilhada. Revista da OAB de Goiás, Ano XII, nº 36.

SANTOS, Aline Cecília Alexandrina Bezerra dos. Multipropriedade imobiliária e a concretização da função social na garantia do acesso à moradia de lazer. Disponível em: http://www.publicadireito.com.br/artigos/?cod=6a0143100dc16755

VENOSA, Silvio de Salvo. Direito civil: reais. 17. Ed. São Paulo: Atlas, 2017.

VIEGAS DE LIMA, Frederico Henrique. Aspectos teóricos da multipropriedade no direito brasileiro. Revista dos Tribunais. 